\title{
Laboreal
}

Volume $6 \mathrm{~N}^{\circ} 2$ | 2010

Varia

\section{Seveso : o desastre e a Directiva}

Seveso : el desastre y la Directiva

Seveso : le désastre et la Directive

Seveso : the disaster and the Directive

\section{Laura Centemeri}

\section{(2) OpenEdition}

\section{Journals}

\section{Edição electrónica}

URL: https://journals.openedition.org/laboreal/8938

DOI: 10.4000/laboreal.8938

ISSN: 1646-5237

Tradução(ões):

Seveso : el desastre y la Directiva - URL : https://journals.openedition.org/laboreal/8950 [es]

\section{Editora}

Universidade do Porto

\section{Refêrencia eletrónica}

Laura Centemeri, «Seveso : o desastre e a Directiva», Laboreal [Online], Volume 6 N² | 2010, posto online no dia 01 octobre 2010, consultado o 28 juin 2022. URL: http://journals.openedition.org/ laboreal/8938 ; DOI: https://doi.org/10.4000/laboreal.8938

Este documento foi criado de forma automática no dia 29 setembro 2020.

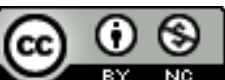

Laboreal está licenciado com uma Licença Creative Commons - Atribuição-NãoComercial 4.0 Internacional. 


\title{
Seveso : o desastre e a Directiva
}

\author{
Seveso : el desastre y la Directiva \\ Seveso : le désastre et la Directive \\ Seveso : the disaster and the Directive \\ Laura Centemeri
}

1 Seveso é um pequeno município italiano, situado a cerca de $22 \mathrm{~km}$ a norte de Milão, cidade capital da região da Lombardia. Seveso faz parte do denominado "distrito do móvel” da Brianza, um território de tradição cultural e política católica. [1]

2 O nome Seveso é associado, em Itália e na Europa, ao acidente industrial, de 10 de Julho de 1976, que causou a contaminação com dioxina de grande parte do território dos municípios limítrofes de Cesano Maderno, Desio e Meda. Trata-se da maior exposição ao TCDD [2], registada até ao momento, de uma população humana (Eskenazi et al., 2001). Ainda hoje continuam a ser efectuados estudos epidemiológicos que analisam as consequências sanitárias do acidente. Seveso dará o nome à Directiva Europeia sobre Riscos de Acidentes Graves (Directiva 82/501/CEE de 24 de Junho de 1982).

\section{0 desastre}

3 O acidente que esteve na origem do desastre de Seveso ocorreu na fábrica de químicos ICMESA, na cidade de Meda. A fábrica pertencia à multinacional farmacêutica suíça Roche. No sábado, 10 de Julho de 1976, por volta das $12 \mathrm{~h} 30 \mathrm{~m}$, o reactor no qual era produzido o triclorofenol, um componente intermédio utilizado na preparação de herbicidas e de uma substância anti-bacteriana (o hexaclorofeno), libertou uma nuvem tóxica de dioxina, na sequência de uma reacção exotérmica inesperada. A nuvem depositou os seus venenos sobre o território das cidades de Meda, Cesano Maderno, Desio e Seveso. Devido à direcção dos ventos, o território de Seveso foi o mais atingido.

Como demonstrou a Comissão Parlamentar de Inquérito sobre o desastre, o acidente esteve directamente relacionado com a falta de investimentos na segurança das instalações da fábrica [3]. A Roche estava, todavia, a par dos riscos da produção de triclorofenol que já tinham surgido em casos anteriores de acidentes industriais. Estes 
riscos devem-se à dioxina, substância que se produz como resíduo durante a transformação do triclorofenol.

5 Em 1976 os estudos epidemiológicos sobre os efeitos da dioxina eram poucos e limitavam-se a casos de trabalhadores da indústria (homens e adultos) expostos acidentalmente a elevadas concentrações de dioxina (Zedda, 1976) que evidenciaram, contudo, os efeitos extremamente nocivos dessa substância para a saúde humana. A contaminação de todo um território e da sua população era um caso sem precedentes. Para além disso, não existia maneira de medir a presença de dioxinas no corpo humano (Mocarelli, 2001). Assim, surgirá a confrontação com uma situação de "incerteza radical" (Callon, Barthe \& Lascoumes, 2001) sobre a extensão e as possíveis consequências da contaminação. Tais consequências eram já, entretanto, concebidas como catastróficas.

O cenário da catástrofe não foi imediatamente conhecido. Os habitantes de Seveso e Meda estavam habituados aos odores incomodativos emitidos periodicamente pela que tinha sido ironicamente baptizada como a "fábrica dos perfumes". E passou-se uma "semana de silêncios" (Fratter, 2006). A Roche anunciou, por fim, a 19 de Julho, que o acidente da ICMESA tinha causado uma fuga de dioxina e sugeria a evacuação da população da área mais gravemente atingida. Os responsáveis pela resposta à crise foram as autoridades da Região da Lombardia com o apoio das autoridades centrais.

7 A evacuação começou a 24 de Julho : 736 habitantes de Seveso e Meda foram obrigados a deixar as suas casas, sem a possibilidade de levarem consigo qualquer objecto pessoal. Entre estes, 200 não puderam regressar uma vez que as suas casas foram destruídas durante os trabalhos de limpeza. Paralelamente, uma comissão de especialistas dividiu o território atingido em "zonas de risco", com base na trajectória estimada da nuvem mas, sobretudo, tendo por referência critérios de sustentabilidade social de uma evacuação de grande dimensão [4]. Daqui resultou uma cartografia da contaminação na qual as zonas de risco eram delimitadas por linhas rectas coincidentes com os limites administrativos ou naturais, o que levou muitos cidadãos a duvidarem da lógica que presidira a tais critérios.

8 A questão que, contudo, suscitou mais conflitos e controvérsia foi a decisão das autoridades regionais de autorizarem os abortos terapêuticos às mulheres grávidas (que se encontravam no limite do terceiro mês de gravidez) residentes na zona contaminada, tendo por base os presumíveis efeitos teratogénicos da dioxina. Naqueles anos, o debate sobre a despenalização do aborto estava no centro da cena política italiana. O caso de Seveso catalisou a atenção dos principais actores do conflito, o que tornou ainda mais trágico e sofrido o dilema que algumas mulheres tiveram que enfrentar em Seveso, num contexto, que recordamos, de cultura fortemente católica (Ferrara, 1977) [5].

9 O modo como a Região da Lombardia respondeu à crise foi marcado por um elevado grau de centralização da decisão. Foram criadas comissões de especialistas às quais foi pedido que fornecessem as soluções necessárias fundadas em decisões unânimes. 0 Conselho Regional pretendia assim poder limitar-se a ratificar a decisão técnica. Deste modo, questões cuja natureza era inextrincavelmente política, científica e social foram reduzidas a problemas técnicos (Conti, 1977).

10 A centralização da decisão e o seu baixo nível de democraticidade explicam os conflitos que surgiram no momento da implementação das medidas tomadas, traduzidos, nomeadamente, nas muitas resistências expressas por parte da população. A 
necessidade de uma maior participação da população afectada pela decisão foi reivindicada tanto pelos movimentos sociais nacionais, mobilizados em Seveso para denunciar os custos do capitalismo a partir de um discurso de crítica social, como pelas comissões espontâneas de cidadãos criadas, na maioria dos casos, em redor das paróquias do território. Movimentos nacionais e comissões espontâneas dividiam-se, contudo, sobre a questão dos abortos terapêuticos, questão que acabou por monopolizar o espaço público (Centemeri, 2006).

11 Movimentos e comissões uniram-se, todavia, na contestação da decisão da Região da Lombardia em construir na Zona A um incinerador no qual seriam queimados os resíduos produzidos pelos trabalhos de descontaminação. Os cidadãos contrapuseram a este plano um projecto de enterrar os resíduos em dois aterros sanitários especiais que seriam construídos na Zona A, dado que a vontade deles era a de ver a Zona A transformada num parque urbano. Depois de dois anos de disputas, a Região da Lombardia decidiu apoiar, por fim, o projecto dos cidadãos.

Entre 1981 e 1984 foram escavados dois aterros na zona A e a descontaminação foi concluída em Dezembro de 1985. Mas, já em 1984 se tinham iniciado os trabalhos para reflorestar a Zona A, transformando-a num parque urbano - o "Bosque dos Carvalhos" e que foi aberto ao público em 1996. Em 2004 foi inaugurado o "Percurso da Memória no Bosque dos Carvalhos", com onze painéis que contam a história do desastre e a origem do bosque. Trata-se do resultado de um complexo trabalho de escrita colectiva da memória do desastre [6].

13 Por outro lado, pode dizer-se que, do ponto de vista do diálogo cidadãos - instituições, Seveso não foi um bom exemplo, à luz da elevada taxa de conflitos que caracterizou a crise e a resposta à crise. Contudo, a recuperação ambiental do território foi um caso de sucesso. Paralelamente à recuperação ambiental, a zona atingida recuperou rapidamente as condições sócio-económicas que caracterizavam o território antes da contaminação.

14 Hoje Seveso é uma cidade na qual várias organizações e associações se empenham em actividades de recuperação e valorização ambiental, mas o desastre continua a estar presente na realidade local com a questão, ainda em aberto, acerca das suas consequências sanitárias.

15 A produção científica sobre os efeitos da dioxina em Seveso é muito significativa. Todavia, esta produção não é objecto de discussão entre a população atingida, cujo grau de participação nos estudos realizados se limitou a responder a questionários ou a submeter-se a idas periódicas ao médico (Centemeri, forthcoming). Além disso, tais estudos acabam por marginalizar os objectivos de saúde pública do território, uma vez que se concentram, a partir de Seveso, sobre a exploração dos mecanismos biomoleculares que explicam os efeitos cancerígenos da dioxina no ser humano.

16 È certo, também, que os estudos epidemiológicos confirmam a diversidade dos efeitos da dioxina sobre a saúde da população atingida, quer em termos dos vários graus de gravidade, quer de frequência (Consonni et al., 2008 ; Baccarelli et al., 2008), apoiando, assim, a classificação efectuada, em 1997, pela International Agency for Research on Cancer (IARC) que reconheceu a dioxina como sendo seguramente cancerígena (grupo 1) para o ser humano (Steenland, Bertazzi, Maccarelli \& Kogevinas, 2004). 


\section{A(s) Directiva(s) "Seveso" : gestão do risco e governance}

17 O acidente de Seveso representou um evento determinante para a definição de uma regulação a nível europeu sobre riscos desta natureza e que acabou por ser preliminarmente fixada na Directiva relativa aos riscos de acidentes graves de certas actividades industriais (82/501/CEE), conhecida como "Seveso 1".

18 O que explica que a Comunidade Económica Europeia, exactamente na sequência do acidente de Seveso, venha afirmar a urgência de uma regulamentação europeia para os riscos de actividades industriais ? São várias as razões. Uma das razões mais fortes foi seguramente a natureza transnacional do acidente ocorrido na ICMESA, mas também o facto de o acidente ocorrer em Itália, no Sul da Europa. Era conhecido nos "meios comunitários" de Bruxelas que a regulamentação italiana, sobretudo em matéria de ambiente e de segurança industrial, estava atrasada relativamente aos países do norte da Europa (van Eijndhoven, 1994).

19 Contudo, o Tratado CEE, na sua versão original de 1957, não previa poderes e competências que permitissem à Comissão ter uma iniciativa legislativa em matéria de riscos industriais no âmbito de uma política de tutela ambiental [7]. A via seguida foi a da harmonização das legislações e regulamentações dos Estados-membros neste domínio, fundamentada no facto da divergência existente "provocar uma distorção nas condições de concorrência do mercado comum" (artigo 100 do Tratado). Foi, aliás, através desta base legal, que permitia colmatar a carência de poderes da CEE em múltiplos domínios, que foram adoptadas, a partir de 1973, as primeiras directivas concernentes à defesa do ambiente.

20 A Directiva 'Seveso 1' concentra-se sobre aspectos de "risk management" que são operacionalizáveis através de obrigações de informação. É neste domínio que se reflecte a influência directa do acontecimento em Seveso : o acidente na ICMESA é considerado, de facto, como um "desastre da informação" (van Eijndhoven, 1994). A questão que sobressai, a partir da experiência do acidente, foi a da falta de informação necessária para que a população atingida e as autoridades responsáveis tivessem podido agir oportunamente depois do acidente. Com efeito, a directiva visa promover uma harmonização das regulamentações nacionais fazendo da comunicação um elemento de segurança primordial neste domínio.

21 Neste sentido, a parte mais inovadora da directiva é a que consta do seu artigo $8^{\circ}$, em matéria de informação ao público, estabelecendo uma obrigação que irá enfraquecer o segredo industrial no âmbito das actividades abrangidas. Simultaneamente, a directiva desenha uma espécie de rede de informação entre as autoridades públicas e a indústria e entre a indústria e as partes potencialmente em risco (Otway, 1990; Otway e Amendola, 1989).

22 Na sequência de novos acidentes, e em virtude dos balanços que foram sendo feitos da aplicação das legislações em vigor, foi adoptada, em 1996, uma nova directiva (Directiva 96/82/CE, de 9 de Dezembro de 1996), que veio substituir a "Seveso I" e que foi apelidada de Directiva "Seveso 2". Entre as importantes alterações introduzidas por esta nova directiva, referiremos o facto de as novas exigências passarem a incidir também no ordenamento do território como elemento integrante da prevenção de 
acidentes graves, em coerência, aliás, com a sua preocupação de se focalizar na protecção do ambiente.

Mas a grande alteração em relação à Directiva "Seveso 1" diz respeito ao modo como passa a ser considerada a informação e a comunicação públicas. Em muitos dos artigos da directiva "Seveso 2", em particular no seu artigo 13르, consagra-se o reconhecimento de um papel activo da população que desenha um "direito à participação", mesmo se ainda embrionário.

A Directiva "Seveso 2" foi, por sua vez, alterada, em 2003, pela Directiva 2003/105/CE do Parlamento Europeu e do Conselho, de 16 de Dezembro de 2003 ("Seveso 3"). A motivar as alterações esteve, entre outros, o acidente, em 21 de Setembro de 2001, na fábrica AZF em Tolosa, uma instalação classificada como "Seveso". Esta directiva passa a incluir as operações de processamento e armazenamento das matérias minerais realizadas pelas indústrias extractivas que envolvam substâncias perigosas e a inovação mais relevante diz, sobretudo, respeito ao alargamento do cumprimento das obrigações de gestão às empresas subcontratadas que trabalhem nos estabelecimentos abrangidos pela normativa "Seveso".

Com as Directivas "Seveso 2 e 3" a concepção da gestão dos riscos desta natureza transformou-se, na medida em que um problema técnico reservado, em princípio, aos especialistas, foi sendo progressivamente configurado e instituído enquanto problema de governance (De Marchi, Pellizzoni \& Ungaro, 2001). E, no caso da União Europeia, enquanto questões de 'governação' relativas à "livre circulação de trabalhadores e política social; condições de trabalho; segurança dos trabalhadores; ambiente; consumidores e proteç̧ão da saúde ; poluição e perturbações ; substâncias químicas, riscos industriais e biotecnologia".

\section{BIBLIOGRAFIA}

Baccarelli, A., Giacomini, S.M., Corbetta, C., Landi, M.T., Bonzini, M., Consonni, D., Grillo, P., Patterson, D.G., Pesatori, A.C. \& Bertazzi, P.A. (2008). Neonatal Thyroid Function in Seveso 25 Years after Maternal Exposure to Dioxin, PLoS Medicine, 5 (7): e161, 1133-1142.

Bagnasco, A. (1977). Tre Italie : la problematica territoriale dello sviluppo italiano. Bologna : Il Mulino.

Callon, M., Barthe, Y. \& Lascoumes, P. (2001). Agir dans un monde incertain. Essai sur la démocratie technique, Paris : Seuil.

Centemeri, L. (2006). Ritorno a Seveso. Il danno ambientale, il suo riconoscimento, la sua riparazione, Milano : Bruno Mondadori.

Centemeri, L. (2010). The Seveso disaster's legacy, in M. Armiero, M. Hall (dir.), Nature and History in Modern Italy. Athens (OH): Ohio University Press \& Swallow Press, pp. 251-273.

Centemeri, L. (forthcoming). What kind of knowledge is needed about toxicant-related health issues? Some lessons drawn from the Seveso dioxin case, in S. Boudia e N. Jas, Powerless Science? The Making of the Toxic World in the Twentieth Century, Oxford and New York: Berghahn Books. 
Consonni, D., Pesatori, A.C., Zocchetti, C., Sindaco, R., Cavalieri D’Oro, L., Rubagotti, M. \& Bertazzi, P.A. (2008). Mortality in a Population Exposed to Dioxin after the Seveso, Italy, Accident in 1976: 25 Years of Follow-Up, American Journal of Epidemiology, 167, 847-858.

Conti, L. (1977). Visto da Seveso : l'evento straordinario e l'ordinaria amministrazione, Milano : Feltrinelli.

De Marchi, B., Pellizzoni, L. \& Ungaro, D. (2001). Il rischio ambientale, Bologna : Il Mulino.

Diamanti, I. (2009). Mappe dell'Italia politica, Bologna : Il Mulino.

Eijndhoven, J. van (1994). "Disaster prevention in Europe." in S. Jasanoff (dir.), Learning from disaster. Risk Management After Bophal, Philadelphia: University of Pennsylvania Press, 113-132.

Eskenazi, B., Mocarelli, P., Warner, M., Samuels, S., Needham, L., Patterson, D., Brambilla, P., Gethoux, P.M., Turner, W., Casalini, S., Cazzaniga, M. \& Chee, W.Y. (2001). Seveso Women's Health Study: Does Zone of Residence Predict Individual TCDD Exposure? Chemosphere, 43, 937-942.

Ferrara, M. (1977). Le donne di Seveso, Roma : Editori Riuniti.

Fratter, M. (2006). Memorie da sotto il bosco, Milano : Auditorium.

Otway, H. (1990). Communicating with the public about major hazards: challenges for European research, in H.B.F. Gow, H. Otway (a cura di), Communicating with the public, New York: Elsevier.

Otway, H. \& Amendola, A. (1989). Major hazard information policy in the European Community: Implications for risk analysis, Risk Analysis, 9, 4, 505-512.

Steenland, K., Bertazzi, P. A. Maccarelli, A. \& Kogevinas, M. (2004). Dioxin Revisited: Developments Since the 1997 IARC Classification of Dioxin as a Human Carcinogen, Environmental Health Perspectives, 112(13), 1265-1268.

Mocarelli P. (2001). Seveso: A Teaching Story, Chemosphere, 43, 391-402.

Sambeth, J. (2004). Zwischenfall in Seveso, Zurich: Unionsverlag

Zedda,S. (1976). La lezione della cloracne, in AA.VV. Icmesa. Una rapina di salute, di lavoro e di territorio, Milano : Mazzotta.

\section{NOTAS}

1. Sobre o "distrito industrial" remeto para o trabalho fundador de Bagnasco (1977). Sobre o mapa político de Itália e a sua evolução, com a divisão que permaneceu até ao inicio dos anos noventa entre regiões "vermelhas" (governo do Partido Comunista) e regiões "brancas" (governo da Democracia Cristã), remeto para Diamanti (2009).

2. A 2,3,7,8-tetraclorodibenzo-p-dioxina (TCDD), conhecida como a dioxina de Seveso, é um subproduto de várias reacções químicas e processos de combustão à base de cloro orgânico.

3. Relatório conclusivo da Comissão Parlamentar de inquérito sobre a fuga de substâncias tóxicas que ocorreu em 10 de Julho de 1976 nas instalações da ICMESA e sobre os potenciais riscos para a saúde e para o ambiente derivados das actividades industriais, Actos Parlamentares, VII legislatura, doc. XXIII, n.6, 1978; veja-se também o livro auto-biográfico do ex-director técnico Givaudan Jörg Sambeth (2004).

4. A Zona A (108 hectares) foi evacuada; a Zona B (269 hectares, 4.600 habitantes) não foi evacuada dado que as concentrações registadas da dioxina foram consideradas como sendo compatíveis com a possibilidade de continuar a habitar o território. Os habitantes foram obrigados a respeitar normas de conduta muito estritas; a Zona de Respeito (1.430 hectares, 
31.800 habitantes) não foi evacuada, porque as concentrações de dioxina eram muito limitadas. Apesar disso, os seus habitantes tiveram que seguir algumas normas de precaução.

5. A interrupção voluntária da gravidez é despenalizada com a Lei 194 de 1978.

6. Sobre a redacção dos painéis remeto para Centemeri $(2006,2010)$. Os painéis podem ser consultados no site: http://www.boscodellequerce.it/pubblicazioni/Informazioni/ Informazioni.asp?ID_M=178

7. É com o Acto Único de 1986, que modifica o Tratado CEE, que são fixados os fundamentos jurídico-políticos da intervenção da Comunidade Económica Europeia em matéria ambiental (artigos $130^{\circ} \mathrm{r}, 130^{\circ}$ s e $130^{\circ} \mathrm{t}$ ).

ÍNDICE

Temas: O Dicionário

\section{AUTOR}

\section{LAURA CENTEMERI}

Centro de Estudos Sociais, Universidade de Coimbra, Colégio de S. Jerónimo, Apartado 3087, 3001-401 Coimbra, Portugal

centemeri@ces.uc.pt 